
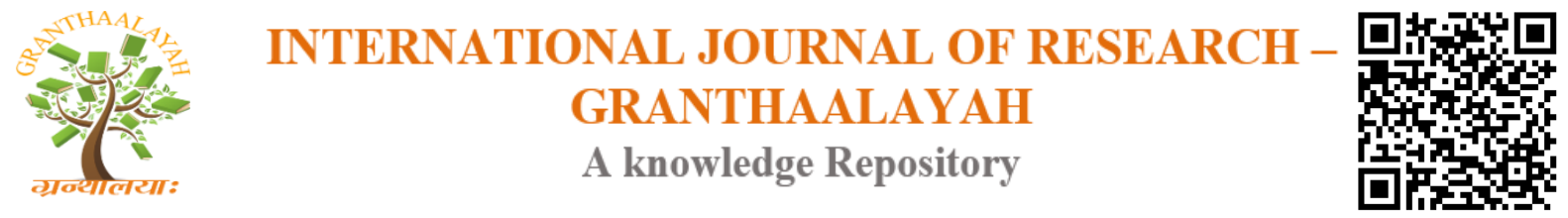

Social

\title{
DETERMINANTS FOR THE DECLINE IN HINDI LANGUAGE STUDENTS IN FIJI NATIONAL UNIVERSITY
}

\author{
Prashneel Ravisan Goundar ${ }^{* 1}$, Preetika A. Prasad ${ }^{2}$ \\ ${ }^{* 1}$ Lecturer, Department of Language and Literature, Fiji National University, Lautoka, Fiji \\ ${ }^{2}$ Bachelor of Education (English \& Hindi) Student, Fiji National University, Lautoka, Fiji
}

\begin{abstract}
In Fiji, the Hindi language is one of the three National languages (English and I-Taukei) used. It is the mother tongue of almost $35 \%$ of Fiji's population attested to the arrival of indentured laborers in the late 1800's which give the country multilingualism. Fiji was previously bilingual with the colonialism, Christian missionaries and explorers bringing the English language. Unfortunately, there is emerging a trend in the decline of tertiary students undertaking studies in the Hindi Language. This paper evaluates the determinants for the decline in Hindi Language students and makes appropriate recommendations.
\end{abstract}

Keywords: Hindi Language; Fiji; Fiji-Hindi; Hindi Language Students.

Cite This Article: Prashneel Ravisan Goundar, and Preetika A. Prasad. (2017). "DETERMINANTS FOR THE DECLINE IN HINDI LANGUAGE STUDENTS IN FIJI NATIONAL UNIVERSITY." International Journal of Research - Granthaalayah, 5(8), 267-276. https://doi.org/10.29121/granthaalayah.v5.i8.2017.2230.

\section{Introduction}

"Language is the blood of the soul into which thoughts run and out of which they grow" (Homes, 2011). Fiji's cultural diversity has enabled it to become a hub of a variety of languages, of which Hindi is prominent. Hindi is the fourth most spoken first language (L1) in the world after Mandarin, English and Spanish. The language owes its roots to Sanskrit from which it flourished around $7^{\text {th }}$ century AD (Hindi Guru Language Institute, n.d.). Since then it has developed into a beautiful language which is proudly spoken by around half a billion of the world's populous. This research has focused on the determinants for the decline in the number of Hindi Language Students in Fiji National University. It has emphasized on the challenges faced by Hindi Language students in Fiji National University and stated ways in which these could be counted.

Worryingly, in today's modern and exhausting life, the root of Hindi language is getting weaker due to a number of irrepressible factors. This in turn has become a tremendous barrier for students seeking to learn Hindi language as a profession, especially in Fiji where from an early age children are immersed in English when it comes to their upbringing and education. The 
employment sector in Fiji also contributes significantly towards this barrier as the English medium is accommodated and strongly enforced among the employees.

The nourishment of an individual's mother tongue is critical as it enhances thinking and develops self-confidence. A Fijian Academic and writer, Subramani (Fiji Islands Education Commission, 2000), states that "it is very important that the mother tongue be given encouragement. Otherwise, children might not respect their own parents, family and community." Also Goundar (2015), states that "it is often observed that due to the concept of high prestige and low prestige, people find that those who speak less of their mother tongue and more of English are considered more intellectual."

Hindi language is one of the vital pillars which holds up and makes possible the growth of traditions and customs of the local Indo-Fijian communities. With regards to this, more effort should be made by the respective stakeholders to ensure that there is a new generation of Hindi language enabled individuals who can disperse quality education to their successors and help the roots grow strong so that the entire tree of culture, tradition and society can flourish and prosper.

\subsection{Statement of the Problem}

This research has focused on the determinants for the decline in the number of Hindi Language students in Fiji National University. It has emphasized the challenges faced by students in Fiji National University and ways in which these could be controlled. It further discusses the ways in which the issues could be tackled.

\subsection{Objective}

The objective of this study was to find out:

- The determinants for the decline in the number of Hindi Language students in Fiji National University

- Challenges which were faced by Hindi Language students in Fiji National University and ways to overcome these challenges

- The measures for improving the number of Hindi Language students in Fiji National University.

\subsection{Significance}

- This research would help the interested shareholders, such as the Ministry of Education, to look for ways in motivating students to take up Hindi at university level so that the quality of Hindi studies in the education system can be improved

- The project would also emphasize on how an increase in the number of Hindi Language students will in turn lead to a decrease in the racial gap between the indigenous iTaukei people and the people of other races, especially those of Indian descent

- This research would provide the researcher with a deeper insight as to why there is a decline in the number of Hindi Language students over the decades and has given the researcher ideas as to how these problems can be alleviated 


\subsection{Research Questions}

- Why is there a decrease in the number of Hindi Language students in Fiji?

- What types of challenges are faced by Fiji National University Hindi Language students?

- What are the measures for improving the number of Hindi Language Students in Fiji National University?

\section{Background}

The roots of Hindi took hold in the isles of Fiji during the so-called Girmit era between 1879 and 1916. The two major reasons which cemented the fate of the indentured labourers from India were the abolishment in 1833 of slavery in the British empire and Sir Arthur Gordon's past experience with the Indian labourers while his time as the Governor of Trinidad and Mauritius (Naidu, 2004).

During the Girmit period, which spanned a total of 39 years, over 60,000 Indian labourers were brought to Fiji to meet the lack of labour demands of the sugarcane, sandalwood and cotton plantation owners. The Girmitiyas were a collection of people from various backgrounds with majority being from Bihar, Calcutta and Madras. The laborers who boarded ships from the ports in Calcutta were statistically 85.3\% Hindus, $14.6 \%$ Muslims and 0.1\% Christians (Ali, 2004). The variety of the religions together with the richness of the dialects from different states merged over the years forming the Fiji-Hindi dialect which is now the common medium used by all Fijians of Indian descent to communicate with each other.

Development and nutriment of languages in any country is essential since it leads to the strengthening of societies and increase the prosperity of a nation as a whole. With Fiji Indians being one of the majority racial groups in the society, the need to introduce Hindi studies in Fiji therefore became paramount. This led to Fiji's Ministry of Education implementing Hindi language studies in primary and secondary school levels. However, the need for advanced mode of Hindi studies remained and this stimulated the regional educational institutions, such as the Fiji National University, to create programs like the Bachelor of Arts in Hindi to cater for the need for Hindi studies.

\subsection{Literature Review}

The decline in the number of Hindi Language students at university level has been a perennial issue of concern for the past three decades. Many researchers and scholars have sought to root out the reasons related to this decline and resolve the problem. According to an article written by Mohammed Wajihuddin of the Times of India, till 1990's there were nearly 400 Hindi master's students at the Mumbai University. However, this number has dropped down to half since that time (Wajihuddin, 2008). Many justify the decline by stating English language as the competitive weed.

A 2005 report "India Education Report" published by the National Center on Education and the Economy states that despite India having fifteen main languages, of which Hindi is prominent and practiced by $30 \%$ of the population, English is ubiquitous. 'In 1997, an India Today survey 
suggested that about a third of the population had the ability to carry on a conversation in English, which was an amazing increase over the estimates of the 1980's, when only about four to five percent of the population were thought to use the language.' It is estimated that there are 350 million English-speaking Indians today and this number surpasses that of both the United States and Great Britain combined (Cheney, 2005). Clearly, the mammoth figures indicate that English is indeed having a profound effect on the mindset of Hindi practitioners and in turn impacting the Hindi language. The fact that many Indian states are now opting to start teaching English as a second language by grade 3 rather than grade 6 further reinforces the theory of Hindi language losing favor as opposed to English among the younger generation. The report also states that even though mother tongue or regional language is the medium of instruction for most Indian primary schools, students from average and above average (elite) families are typically sent to English medium schools as English is considered a distinction of class.

Ramiji Tiwari, a former Hindi teacher at the Mumbai University states in the article by Mohammed Wajihuddin that 'earlier students would take pride in their rashtra bhasha (National language). Now learning the National language is no longer a matter of pride' (Wajihuddin, 2008). Jain (n.d) of New Delhi states that the reducing use of Hindi and hence Hindi Language students may possibly be an effect of group polarization. Jain (n.d) states that "today's generation reads more in English to gain knowledge from around the world and be at par with the best in the world".

However, not all readily point the finger at the English language when it comes to the decline of Hindi Language students at university level. Kumar believes that lack of commercialization is responsible for the decline in Hindi literature. He states that "the decline is not actually quality wise, but is more so by lack of exposure" (2015). What Kumar (2015) implies is that despite the constant stream of quality Hindi novels being published, neither the hardworking authors nor the publishers are able to earn decent amounts due to the capitalization by English language books in the market. He further states that in order to maximize the exposure of Hindi and reinstall interest in the people, publishers need to be creative and develop a market which is reader based and attracts many. Blogger Ranjit Pratap Singh writes "my personal experience and understanding is that the primary reason is inaccessibility" (Singh, n.d).

\section{Methodology}

In order to compile this research, numerous research methods were used which are listed below.

\subsection{Population and Sampling}

Questionnaires were distributed among 10 students majoring in Hindi; with 5 students from first year, 3 students from second year of study and 2 third year students. The age group of these individuals ranged from 19 to 24 years.

\subsection{Instrumentation}

The study was analyzed by:

- Open ended questionnaires, 
- Face to face interviews. To broaden the scope of data collection, interviews were carried out with the individuals relating to Hindi studies

- Personal observations-was another mode selected for data collection. This enabled the researchers to observe firsthand the decline in the number of Hindi Language students in Fiji National University.

\subsection{Scope and Limitations}

Some of the limiting factors which may hinder the compilation of this research project include:

- Obtaining sincere response from students

- Getting the questionnaires back in time

\section{Results and Discussion}

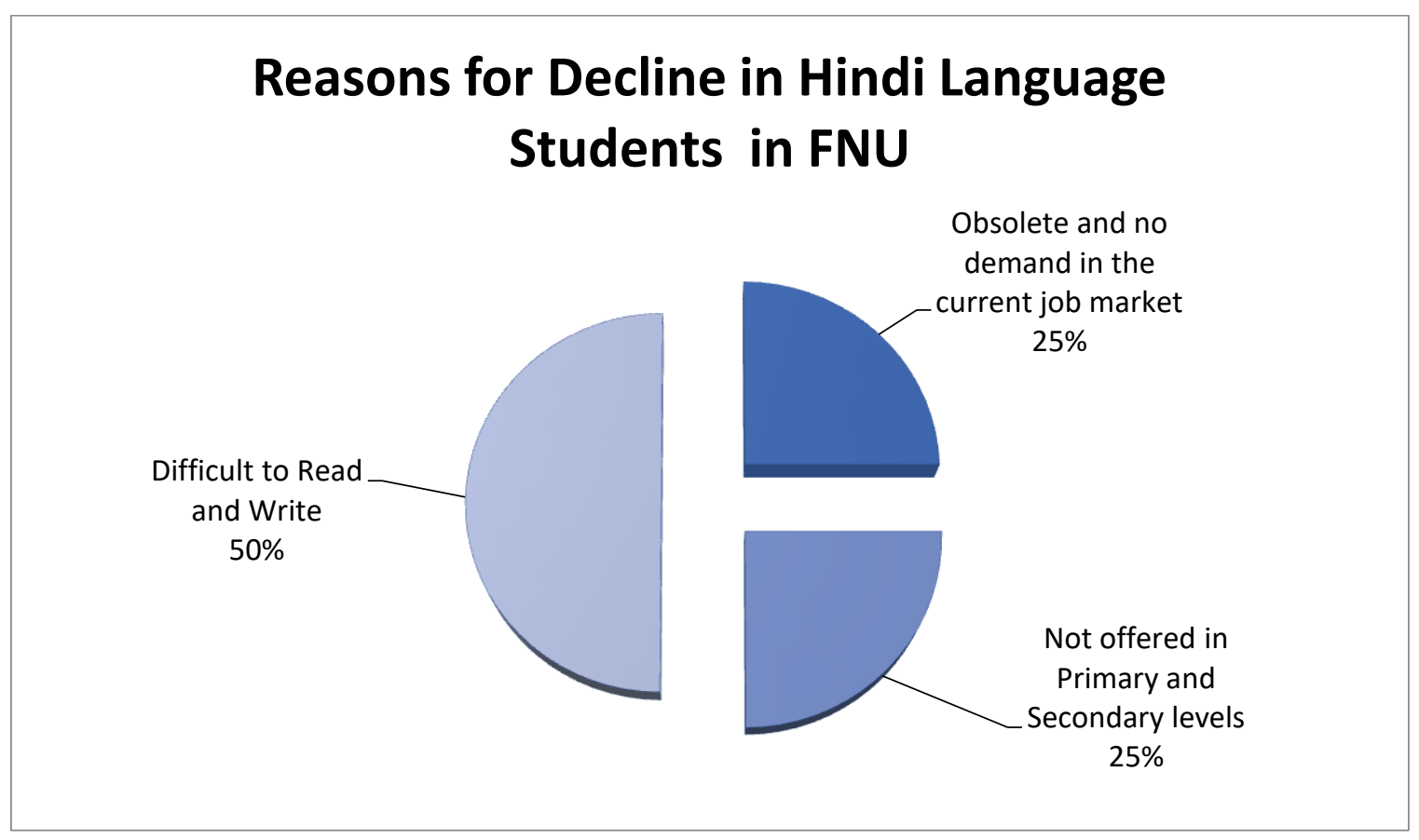

Figure 1: Reasons for Decline in Hindi Language Students

\section{Analysis:}

The analysis of the questionnaires revealed that $50 \%$ of the students believed that the reason for the decline in Hindi Language students at the university level is due to the fact that students find Hindi to be difficult, especially when it comes to reading and writing. The Hindi language may very well be one of the toughest languages of the world as the language utilizes complex scripts and forms to materialize itself, and this adds on to the level of difficulty for those trying to master it. $25 \%$ of the students accredited the decreasing number of Hindi Language students to the low demand of Hindi in the current job market and think of it as an obsolete field of study.

The effects of modernization has rendered the present generation more prone towards technology than arts, thus reducing the interest and hence the number of students interested in becoming 
linguists, especially in the case of Hindi. This in turn has led to significant decline in Hindi Language students and affected the status of Hindi in the employment sector. The remaining $25 \%$ of the students believed that because Hindi is offered only in a limited number of primary and secondary schools, students who are interested to study Hindi are deprived of the opportunity. Due to lack of resources, both intellectual and material; especially in Fiji, Hindi has not been able to strengthen its roots thus limiting its exposure to potential students.

\section{Should Hindi be Compulsary in Primary and Secondary Schools}

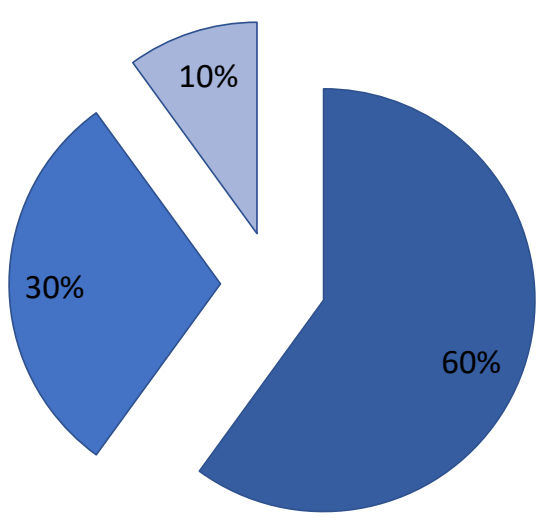

Mother tongue

Gives a sense of identity

$\square$ Helps maintain our Traditions and Culture

Figure 2: Should Hindi be compulsory in Primary and Secondary Schools

\section{Analysis:}

All of the students agreed that Hindi should be made compulsory at primary and secondary school levels. The bulk of the students, nearly $60 \%$, justified their answer by stating that Hindi is their mother tongue and needs to be acknowledged and brought into the education system. The entire Indo-Fijian population in Fiji makes use of Hindi daily to communicate and socialize with their fellow Indo-Fijians. Not only that; but many native Fijians (iTaukei), have also started using Hindi to communicate with their Indo-Fijian neighbours and friends at schools and workplaces. This could infer that Hindi is a vital part of society building in the Fijian communities and simply cannot be ignored.

Another group of students, 30\%, responded that the reason Hindi should be made compulsory is that it gives a sense of identity and belonging. Despite being thousands of miles away from the Indian subcontinent, the Indo-Fijians through the language feel connected to their ancestry and have pride in knowing about their roots and heritage. A small portion, that is; $10 \%$ of the students said that 'Hindi is the vessel through which we maintain our traditions and culture and that is why emphasis should be placed on it'. In all cultural and traditional aspects, whether it is pooja (prayer), ceremonies or cultural discourse, Hindi is the medium through which it is conveyed and practiced. 


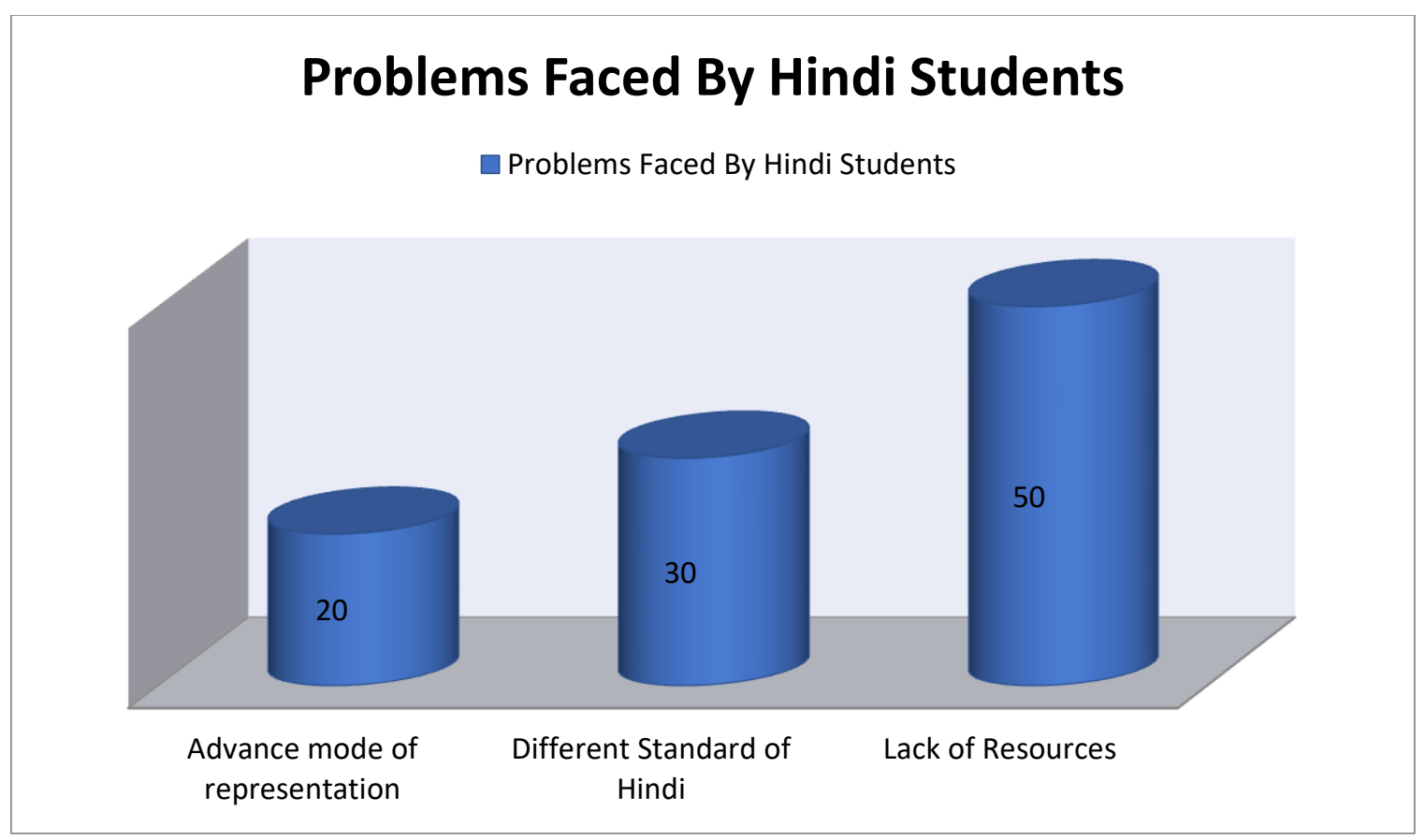

Figure 3: Problems faced by Hindi Language Students

\begin{abstract}
Analysis:
Hindi Language students are faced with a range of challenges during their duration of study. Students stated that the bulk of these challenges, nearly 50\%, are experienced by first year Hindi Language students who find the atmosphere when it comes to Hindi and the higher standard of Hindi teaching to be more challenging than that of their previous education levels. The transition from secondary to tertiary introduces students to advance modes of teaching. This is designed to uplift the quality of the students' knowledge in the subject, however if not properly structured may result in discomfort at the expense of students'. 30\% of the students attributed the challenges faced by them to the lack of resources, especially prescribed text books, which hindered their ability to learn and do research.
\end{abstract}

As mentioned earlier, Fiji being a developing island nation may not always have the resources necessary to cater for the needs of Hindi Language students. Resources such as novels, poems and articles in Hindi remain limited and prevent students from benefiting from them. Advance mode of representation, which is the typing of Hindi projects using the Dev Nagrik software, was selected by $20 \%$ of the students as the reason behind the challenges they faced. Having introduced to the software for the first time at the tertiary level, students often struggled with it and have to invest in a vast amount of time to learn it. 


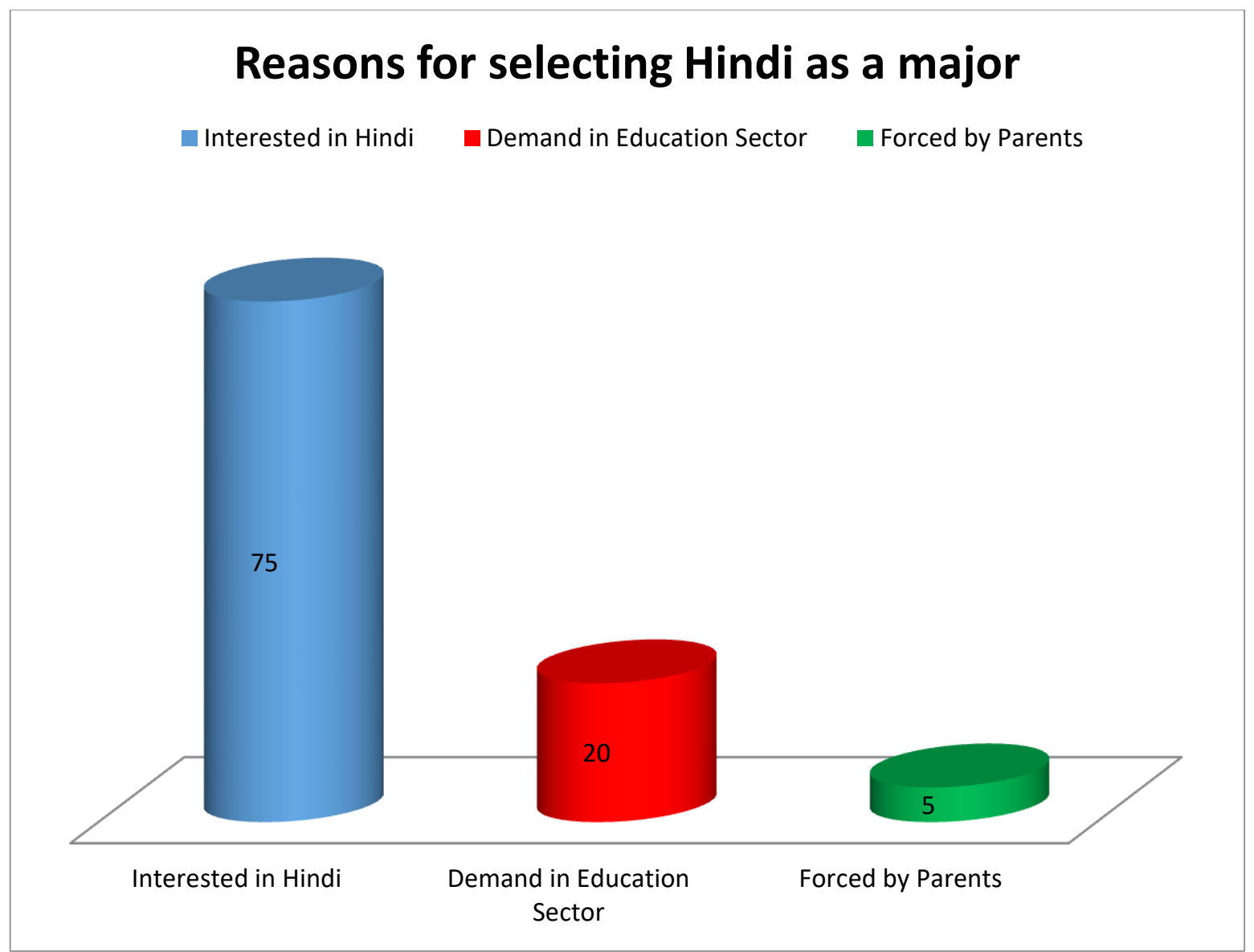

Figure 4: Reasons for selecting Hindi as a major

\section{Analysis:}

Upon analysis, it was revealed that $75 \%$ of the students chose Hindi as one of their majors because it is their mother tongue and they find it to be an interesting subject, one which they are able to easily understand. $25 \%$ chose to take up Hindi since they distinguish it's in demand in the current education sector and provides them with a stable job opportunity.

The difficulties associated in learning Hindi has created an opportunity for those that desire to enter this field at a professional level, especially after the government's decision to make compulsory the learning of basic Hindi language for iTaukei students in some parts of the country.

The remaining 5\% of the students said that Hindi was not their choice of study but was rather selected for them by their parents. There are still some families in Fiji who considered Hindi to be an important part of their lives and encourage their children to take it up as a career. 


\section{Perception on artciulaing feelings or thoughts using Hindi (mother tongue)}

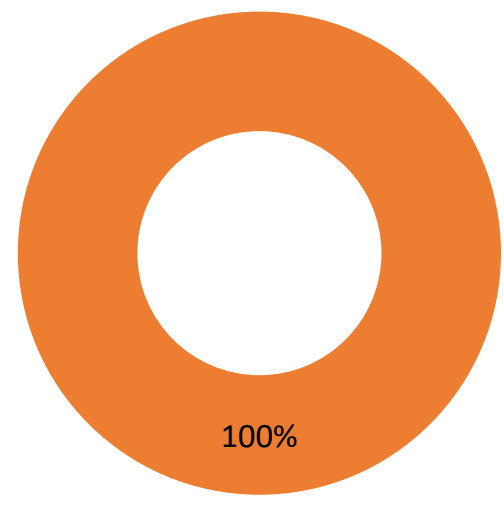

Easier to express

Figure 5: Perception on articulating feelings or thoughts using Hindi Language (Mother Tongue)

\section{Analysis:}

All of the students agreed that Hindi, which is their mother tongue, is a much more convenient way to express their thoughts and feelings compared to other languages. These students said that through Hindi they are easily able to communicate with each other and respond appropriately. Naturally, any individual may find articulating his or her thoughts, feelings and desires smoother when done using their mother tongue. Hindi is not only a language for study but it is an indissoluble part of people's lives. Embedded in the language are many forms of values which helps build character.

\section{Conclusion}

This research has found determinants for a decrease in the number of Hindi Language students in Fiji National University and how it impacts the education system. It has also emphasized on how the number of Hindi Language students in Fiji National University can be improved. There were various instruments used to gather information for this study such as distribution of questionnaire, face to face interviews, and personal observations.

\section{Recommendation}

The researchers suggest measures that if taken inconsideration can reduce the decline in Hindi language students:

- Firstly, students need to be motivated and introduced to Hindi from a younger age so that their interest in Hindi grows. Here, the parents need to be more aggressive as the initial stage of language learning is crucial. 
- More scholarships for Masters and PhDs need to be made available through the Government of India and job opportunities need to be created so that students get attracted towards Hindi and the numbers in Hindi swell.

- Hindi should also be made compulsory in primary and secondary school levels so that the intellect and hence the quality of Hindi Language Students rise.

- The availability of more resources, such as text books, would also result in Hindi Language students doing research with ease and getting better understanding of topics.

\section{Reference}

[1] (n.d.). Retrieved from Hindi Guru Language Institute: htttp://www.hindiguru.org

[2] Ali, A. (2004). Girmit: Indian indenture experience in Fiji. Fiji Museum.

[3] Cheney, G. R., Ruzzi, B. B., \& Muralidharan, K. (2005). India Education Profile. New Commission on the Skills of the American Workforce. Washington, DC: National Center on Education and the Economy (NCEE). http://www. ncee. org/wp-content/uploads/2010/04/IndiaEducation-Report. pdf.

[4] Goundar, P. R. (2016). Defining culture, heritage and identity in Fijian Context. International Journal of Humanities and Cultural Studies (IJHCS) ISSN 2356-5926, 2(1), 239-249.

[5] Homes. 2011. Inspirational Quotes For Language Learners. Retrieved from Voxy Blog.

[6] Importance of Language. (2016, March). Retrieved from Importance of Hindi Language

[7] Jain, S. (n.d.). What is the future of the Hindi language? Retrieved from Quora.

[8] Kumar, J. (2015, May 21). What is responsible for the declinein hindi literature? Retrieved March 12, 2017, from Quora: www.Quora.com

[9] Kumar, J. 2015. What is responsible for the declinein hindi literature? Retrieved March 12, 2017, from Quora: www.Quora.com

[10] Naidu, V. (1980). The violence of indenture. World University Service, in association with the School of Social and Economic Development, University of the South Pacific, Suva.[Also reprinted by Fiji Institute of Applied Studies (F'lAS), Lautoka, 2004].

[11] Singh, R. P. (n.d.). Why Don't Young And Cool Indians Read Any Hindi Literature? Retrieved from Quora: http://www.quora.com

[12] Singh, R. P. (n.d.). Why Don't Young And Cool Indians Read Any Hindi Literature? Retrieved from Quora: http://www.quora.com

[13] Fiji Islands Education Commission/Panel, \& Fiji. Ministry of Education. (2000). Learning together: Directions for education in the Fiji Islands. Government of Fiji, Ministry of Education.

[14] The Importance of Hindi. (2013, September). Retrieved from One Hour Translation

[15] Wajihuddin, M. 2008. Does Hindi Have a Future? The Times of India

*Corresponding author.

E-mail address: prgoundar@ gmail.com 